\title{
Why is there discordance between calcific aortic stenosis and coronary artery disease?
}

There are many similarities in the disease processes of calcific aortic stenosis and coronary artery disease. Both increase in prevalence with age, but neither is thought to be a normal consequence of aging. Calcific aortic stenosis is present in $2-3 \%$ of adults over age 65 years and irregular aortic valve thickening without obstruction to left ventricular outflow (aortic sclerosis) is present in about 25\% of elderly adults. ${ }^{12}$ The presence of an abnormal aortic valve on echocardiography is associated with the same clinical factors, at a similar level of risk, as have been associated with coronary artery disease. Specifically, older age, male sex, increased serum low density lipoprotein (LDL) and $\mathrm{Lp}$ (a) lipoprotein concentrations, smoking, hypertension, and diabetes are associated with calcific aortic valve disease. $^{13-5}$

Calcific aortic valve disease, ranging in severity from sclerosis to stenosis, is characterised by irregular areas of increased thickening on the aortic side of the valve. Grossly, these areas are opaque, yellowish-white, and are firm on palpation. Microscopically these areas contain evidence of chronic inflammation, with infiltration of macrophages and $\mathrm{T}$ lymphocytes. Accumulation of plasma lipoproteins, including LDL and Lp(a) lipoprotein, is present ${ }^{6}$ and a recent study has shown that these lipoproteins are oxidatively modified. ${ }^{7}$ In addition, microscopic calcification is present in these early lesions with localisation to areas of lipoprotein accumulation. ${ }^{6}$ These lesions develop not only in the subendothelium, on the aortic side of the leaflet, but also extend into the adjacent fibrosa, the dense central collagenous layer of the aortic valve (fig 1)

In addition to similarities in prevalence, associated clinical factors, and pathology between aortic sclerosis and coronary disease, further support for a link between these two diseases is based on clinical outcomes in adults with aortic sclerosis. In the population based cardiovascular health study, the presence of aortic sclerosis on echocardiography in adults over age 65 years, with no known coronary artery disease at study entry, was associated with a $50 \%$ increased risk of cardiovascular mortality and myocardial infarction over a mean follow up interval of 5.5 years. ${ }^{8}$ Although further studies are needed both to replicate this finding and to establish the mechanism of this association, it is unlikely that aortic sclerosis directly leads to adverse cardiovascular outcomes. Instead it is probable that aortic sclerosis is a marker of subclinical coronary disease.

However, despite the evidence linking aortic stenosis and atherosclerosis, these disease processes are not synonymous. In adults with severe aortic stenosis, only about $50 \%$ have significant coronary artery disease. Conversely, most patients with coronary artery disease do not have aortic stenosis. At the tissue and cellular level, few smooth muscle cells are present in the aortic valve leaflets. In addition, the degree of calcification is greater in the aortic valve than in the vessel wall. However, perhaps the most important difference is the mechanism of clinical events. In atherosclerosis, plaque instability is key; in aortic stenosis, the shear bulk of the lesion is the problem. Early in the disease process, small areas of inflammation and lipid infiltration are interspersed with areas of normal leaflet so that the valve leaflets remain flexible and open normally in systole. Late in the disease process, the abnormal areas become confluent with prominent calcification and increased fibrosis, resulting in increased leaflet stiffness and obstruction to left ventricular outflow (table 1). These differences between aortic valve and coronary disease suggest that other, as yet unexamined, factors account for the development of clinically evident valvar as opposed to vascular lesions in an individual patient.
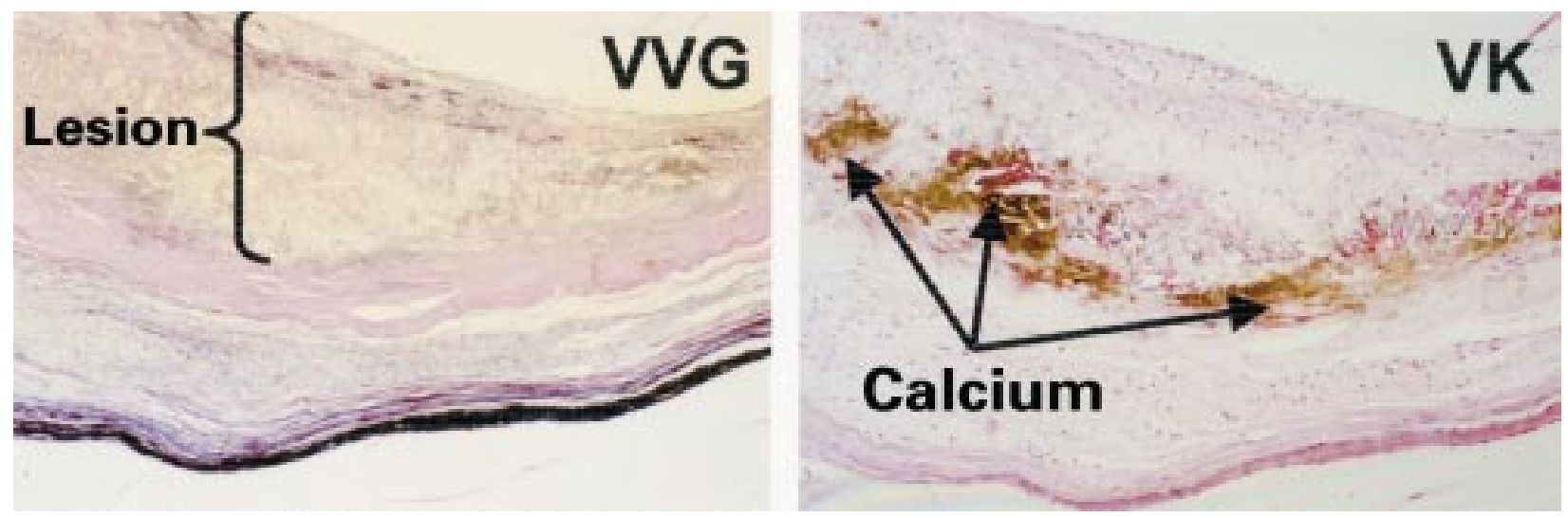

Figure 1 Example of the early lesion of aortic stenosis. The Verhoeff Von Gieson (VVG) stain (left) shows how the lesion involves both the subendothelial region and the adjacent fibrosa. The von Kossa (VK) stain (right) shows regions with microscopic calcification. 
Table 1 Comparison of calcific aortic valve disease and atherosclerosis

\begin{tabular}{lll}
\hline & $\begin{array}{l}\text { Calcific aortic } \\
\text { valve disease }\end{array}$ & Atherosclerosis \\
\hline Clinical & & \\
Increased prevalence with age & ++++ & ++++ \\
$\quad$ Association with clinical factors & ++++ & ++++ \\
Pathologic & +++ & ++ \\
Inflammatory cells & +++ & +++ \\
Lipid infiltration & ++++ & ++ \\
$\quad$ Calcification & $?+$ & +++ \\
Genetic factors & Leaflet stiffness & Plaque instability \\
Mechanism of clinical events & & \\
& &
\end{tabular}

A genetic marker for calcific aortic stenosis?

The paper by Ortlepp and colleagues ${ }^{9}$ in this issue of Heart is the first study to suggest an association between a specific genetic marker and calcific aortic stenosis. In this case control study, the prevalence of a vitamin $\mathrm{D}$ receptor polymorphism (VDR Bsml B/b) was examined in 100 adults undergoing cardiac catheterisation for aortic stenosis, and in a control group of 100 adults undergoing catheterisation for suspected coronary disease, who were matched for age, sex, and prevalence of coronary disease. Compared to controls, the $\mathrm{B}$ allele of the vitamin $\mathrm{D}$ receptor was more frequent than the $\mathrm{b}$ allele in adults with aortic stenosis. Interestingly, the B allele has been associated in some studies with low bone mineral density, impaired calcium absorption, more rapid bone loss, and raised parathormone concentrations. The authors speculate that the $\mathrm{B}$ allele may predispose patients to extraosseous calcification via adaptive mechanisms to counter the negative effects on bone density. Alternatively, the B allele may be in linkage disequilibrium with another, unidentified gene involved in calcium metabolism. In either case, this apparent association suggests that genetic factors related to calcium metabolism may be important in an individual patient's susceptibility to develop valvar calcification. However, it should be noted that it is still a matter of debate not only how the VDR B/b polymorphism might influence bone density, but also whether this polymorphism truly affects bone density. Therefore, the apparent association between the VDR B allele and calcific aortic valve disease must be confirmed in additional studies before firm conclusions can be drawn about its role in this process.

\section{Role of systemic calcium metabolism}

Overall, the relative importance of systemic calcium metabolism versus local tissue factors in the deposition of calcium in the aortic valve leaflets requires further study. The role of local factors in calcification of the native aortic valve is now well established. In the aortic valve lesions, a subset of activated macrophages produce osteopontin, a protein involved in tissue calcification..$^{10}{ }^{11}$ In addition, it is clear that microscopic calcification first forms in areas in which lipoproteins have been retained. ${ }^{6}$ However, the mechanisms by which lipid deposition and microscopic calcification might be linked are not known. It is possible that the effects of vitamin $\mathrm{D}$ receptor polymorphism are seen at the aortic leaflet tissue level as well.

The role of systemic calcium metabolism in valve calcification is less clear. An increased prevalence of premature aortic valvar calcification has been reported in several groups of patients with altered calcium metabolism- including those with hyperparathyroidism, Paget's disease, and renal failure - and some of these patients develop clinically significant valve obstruction. ${ }^{12-14}$ However, unlike the typical elderly patient with calcific aortic valve disease, patients with altered calcium metabolism often have diffuse cardiac calcification, with the disease process involving the mitral valve and annulus, coronary arteries, myocardium, and conduction system, as well as the aortic valve. In addition, factors other than altered calcium metabolism, such as a high output state, may affect the disease process. It also is unknown whether the disease process at the tissue level is similar in patients with altered calcium metabolism compared to patients with isolated calcific aortic stenosis.

\section{Future directions}

Now that an apparent association of a specific genetic factor with aortic stenosis has been described, further studies are needed. Is there evidence of vitamin $\mathrm{D}$ activity in the aortic valve leaflets or is this association mediated through an effect on systemic calcium metabolism? Studies of vitamin $\mathrm{D}$ receptor polymorphism in specific groups with an increased prevalence of calcific valve disease, such as those with renal failure, also would be of interest. Does vitamin D receptor polymorphism explain why some patients in these higher risk groups develop obstructive valve disease while others do not? Long term, further insights into the genetic factors associated with aortic stenosis may allow us to target future medical treatment to the patients at highest risk.

CATHERINE M OTTO KEVIN D O'BRIEN

Division of Cardiology,

Department of Medicine,

University of Washington School of Medicine,

Seattle, Washington,

USA

cmotto@u.washington.edu

1 Stewart BF, Siscovick D, Lind BK, et al. Clinical factors associated with calcific aortic valve disease. F Am Coll Cardiol 1997;29:630-4

2 Lindroos M, Kupari M, Heikkila J, et al. Prevalence of aortic valve abnormalities in the elderly: an echocardiographic study of a random population sample. $f$ Am Coll Cardiol 1993;21:1220-5.

3 Boon A, Cheriex E, Lodder J, et al. Cardiac valve calcification: characteristics of patients with calcification of the mitral annulus or aortic valve. Heart 1997;78:472-4.

4 Mohler ER, Sheridan MJ, Nichols R, et al. Development and progression of aortic valve stenosis: atherosclerosis risk factors-a causal relationship? A clinical morphologic study. Clin Cardiol 1991;14:995-9.

5 Aronow WS, Schwartz KS, Koenigsberg M. Correlation of serum lipids, calcium, and phosphorus, diabetes mellitus and history of systemic hypertension with presence or absence of calcified or thickened aortic cusps or root in elderly patients. Am f Cardiol 1987;59:998-9.

6 O'Brien KD, Reichenbach DD, Marcovina SM, et al. Apolipoproteins B, (a) and $\mathrm{E}$ accumulate in the morphologically early lesion of "degenerative" valvular aortic stenosis. Arterioscler Thromb Vasc Biol 1996;16:523-32.

7 Olsson M, Thyberg J, Nilsson J. Presence of oxidized low density lipoprotein in nonrheumatic stenotic aortic valves. Arterioscler Thromb Vasc Biol 1999;19:1218-22.

8 Otto CM, Lind BK, Kitzman DW, et al. Association of aortic-valve sclerosis with cardiovascular mortality and morbidity in the elderly. $N$ Engl f Med 1999;341:142-7.

9 Ortlepp JR, Hoffmann R, Ohme F, Lauscher J, Bleckmann F, Hanrath P. The vitamin D receptor genotype predisposes the development of calcific

10 O'Brien KD, Kuusisto J, Reichenbach DD, et al. Osteopontin is expressed in human aortic valvular lesions. Circulation 1995;92:2163-8.

11 Mohler ERI, Adam LP, McClelland P, et al. Detection of osteopontin in calcified human aortic valves. Arterioscler Thromb Vasc Biol 1997;17:547-52.

12 Stefenelli T, Mayr H, Bergler-Klein J, et al. Primary hyperparathyroidism: incidence of cardiac abnormalities and partial reversibility after successful parathyroidectomy. Am F Med 1993;95:197-202.

13 Nestico PF, DePace NL, Kimbiris D, et al. Progression of isolated aortic stenosis: analysis of 29 patients having more than 1 cardiac catheterization. Am f Cardiol 1983;52:1054-8.

14 Maher ER, Young G, Smyth-Walsh B, et al. Aortic and mitral valve calcification in patients with end-stage renal disease. Lancet 1987;ii:875-7. 